\title{
Development and physiology of the rumen and the lower gut: Targets for improving gut health ${ }^{1}$
}

\author{
Michael A. Steele, ${ }^{* 2}$ Greg B. Penner, $†$ Frédérique Chaucheyras-Durand, $\ddagger$ and Le Luo Guan* \\ *Department of Agricultural, Food and Nutritional Science, University of Alberta, Edmonton, Canada, T6G 2P5 \\ †Department of Animal and Poultry Science, University of Saskatchewan, Saskatoon, Canada, S7N 5A2 \\ †Lallemand Animal Nutrition, Blagnac, France, 63122
}

\section{ABSTRACT}

The gastrointestinal epithelium of the dairy cow and calf faces the challenge of protecting the host from the contents of the luminal milieu while controlling the absorption and metabolism of nutrients. Adaptations of the gastrointestinal tract play an important role in animal energetics as the portal-drained viscera accounts for $20 \%$ of the total oxygen consumption of the ruminant. The mechanisms that govern growth and barrier function of the gastrointestinal epithelium have received particular attention over the past decade, especially with advancements in molecular-based techniques, such as microarrays and next-generation DNA sequencing. The rumen has been the focal point of dairy cow and calf nutritional physiology research, whereas the lower gut has received less attention. Three key areas that require discovery-based and applied research include (1) early-life intestinal gut barrier function and growth; (2) how the weaning transition affects function of the rumen and intestine; and (3) gastrointestinal adaptations during the transition to high-energy diets in early lactation. In dairy nutrition, nutrients are seen not only as metabolic substrates, but also as signals that can alter gastrointestinal growth and barrier function. Nutrients have been shown to affect epithelial cell gene expression directly and, in concert with insulinlike growth factor, growth hormone, and glucagon-like peptide 2, play a pivotal role in gut tissue growth. The latest research suggests that ruminal and intestinal barrier function is compromised during the preweaning phase, at weaning, and in early lactation. Gastrointestinal barrier function is influenced by the presence of metabolites, such as butyrate, the resident microbiota,

Received September 5, 2015.

Accepted January 15, 2016.

${ }^{1}$ Presented as part of the ADSA Production Division Symposium: The Rumen and Beyond - Nutritional Physiology of the Modern Dairy Cow at the ADSA-ASAS Joint Annual Meeting, Orlando, Florida, July 2015.

${ }^{2}$ Corresponding author: masteele@ualberta.ca and the microbes provided in feed. In the first studies that investigated barrier function in cows and calves, it was determined that the expression of genes encoding tight junction proteins, such as claudins, occludins, and desmosomal cadherins, are affected by age and diet. Recent evidence suggests that the upper and lower gut can communicate, but the exact mechanisms of gastrointestinal cross-talk in ruminants have not been studied in detail. A deeper understanding of how diet and microbiota can affect growth and barrier function of the intestinal tract may facilitate the development of specific management regimens that could effectively influence gut function.

Key words: rumen, lower gut, gut function

\section{INTRODUCTION}

The primary roles of the gastrointestinal epithelium (GE) are to protect the host from the mixture of microorganisms, toxins, and chemicals in the lumen and to prevent unregulated movement of these compounds into the lymphatic or portal circulation (Gäbel et al., 2002). The GE continuously senses the luminal composition to protect against threats to its integrity and enhance nutrient absorption (Furness et al., 2013). In addition to protecting the host, the GE controls nutrient absorption, metabolism, and delivery of nutrients to other body tissues. The gastrointestinal tract (GIT) plays a significant role in animal energetics as it utilizes $20 \%$ of the oxygen in the whole animal and accounts for $30 \%$ of metabolic and protein synthesis activities of the cow (Cant et al., 1996). Thus, although adaptations to the gut are local, they can influence the entire dairy cow or calf system.

Study of the ruminal epithelium has expanded over the last $5 \mathrm{yr}$, with particular attention being paid to the modulation of ruminal function in response to increasing rapidly fermentable carbohydrates (Penner et al., 2011; Steele et al., 2011a,b) and butyrate supplementation (Górka et al., 2011; Baldwin et al., 2012; Kowalski et al., 2015). However, the mechanisms controlling GE 
responses, especially in the lower gut, during dietary adaptation are poorly understood. Moreover, microbes and digesta metabolites and their effects on the function and expression of genes of the lower gut are not well characterized, thus generating the need for further research. The ability to modulate gut epithelial function using nutrients and feeding schemes is of relevance and interest to the dairy industry as it will improve dairy cow and calf health and performance.

\section{COMPARATIVE STRUCTURE OF EPITHELIA}

The contents of the gastrointestinal lumen are separated from the lymphatic and portal circulation by 2 distinct epithelia: the stratified squamous epithelium (SSE) found in the reticulo-rumen and omasum (Figure 1A; Figure 2) and the columnar epithelium (CE) of the abomasum, small intestine, cecum, and large intestine, otherwise known as the lower gut (Figure 1B; Figure 2). In the reticulo-rumen and omasum, the SSE epithelial surface area is increased by papillae that protrude from the ruminal epithelium to increase absorption of shortchain fatty acids (SCFA) and minerals (Lavker and Matoltsy, 1970) and secretion of bicarbonate into the lumen (Aschenbach et al., 2011). The reticulo-ruminal and omasal SSE is composed of 4 distinct strata with multiple functions (Figure 1A). The stratum basale is the first cell layer adjacent to the basal lamina and to the stratum spinosum. The cells of the both the stratum basale and spinosum contain mitochondria that contribute to the metabolic properties of the ruminal SSE, including the metabolism of SCFA to ketones (Baldwin et al., 2004b). Adjacent to the stratum spinosum is the stratum granulosum, which is characterized by tight junctions (occludins, claudins), adherin junctions, and desmosomes, which add mechanical strength to the epithelium (Graham and Simmons, 2005). The stratum corneum is in direct contact with the ruminal and omasal contents and consists of dead cornified keratinocytes (Steele et al., 2011b). The corneum acts as protective barrier between the rumen contents and the lower living strata and is eventually sloughed into the rumen milieu (Graham and Simmons, 2005). Epimural microbes colonize the surface of the corneum but do not penetrate to the stratum granulosum (Steele et al., 2011b). The exact mechanisms controlling how cells differentiate and migrate through the highly metabolic regions of the basale and spinosum to the protective
A

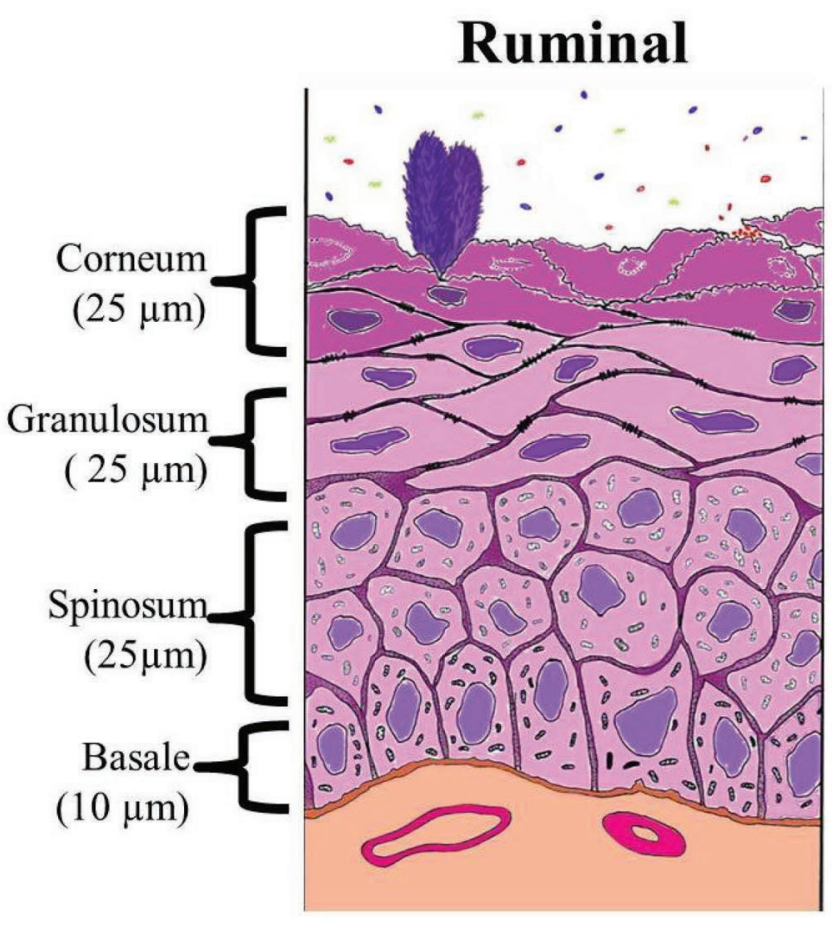

B

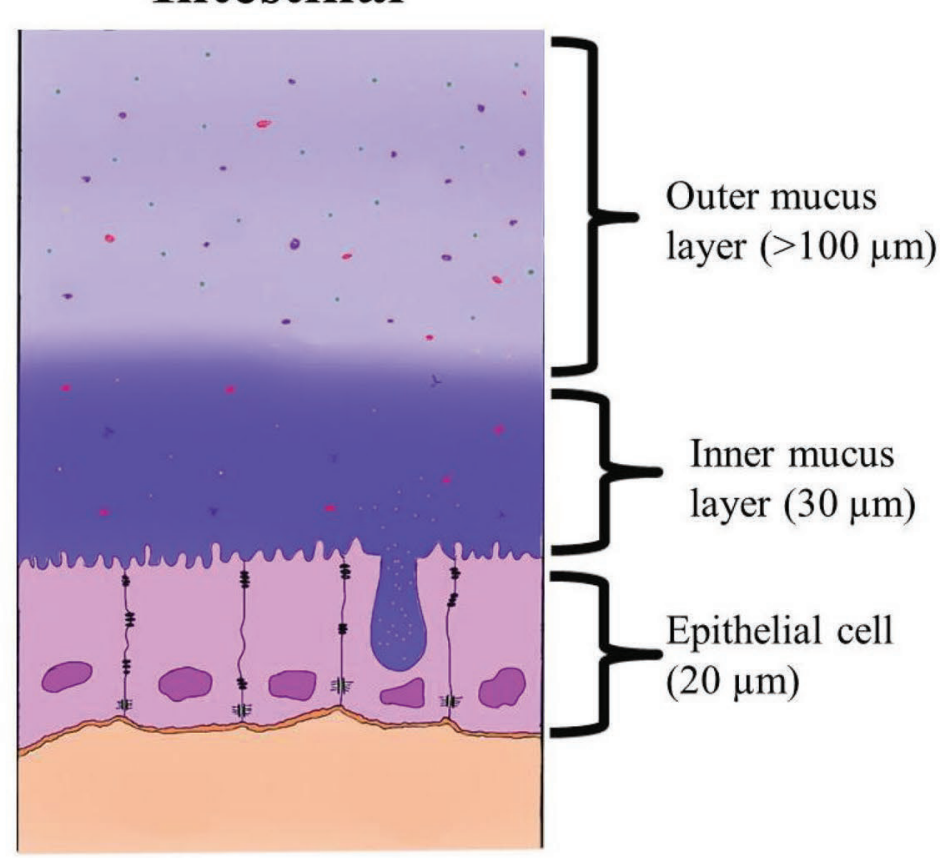

Figure 1. The large contrast of the ruminal and intestinal epithelia. (A) Stratified squamous epithelium of the rumen, and (B) columnar epithelium of the lower gut. 
regions of the granulosum and finally the corneum are unknown.

The characteristics of the lower gut are dramatically different from those of the reticulo-rumen and omasum for several reasons. First, instead of multilayered SSE, there is a simple CE in the lower gut (Figure 1B). The cells of the lower gut encompass absorptive epithelial cells, mucus-secreting cells (goblet cells), immune cells (Peyer's patches, Paneth cells, dendritic cells, and lymphocytes), and enteroendocrine cells (Peterson and Artis, 2014; Figure 2). These specialized cells carry out essential processes; for example, they secrete protective substances (e.g., mucus, antimicrobial peptides) into the lumen, secrete enzymes into the lumen, facilitate nutrient absorption, and secrete hormones [e.g., peptide YY, glucagon-like peptide (GLP)-1, and GLP-2]. In contrast, the ability of the reticulo-ruminal epithelium to secrete antimicrobial compounds (e.g., IFN- $\gamma$ ) has been speculated but not proven (Trevisi et al., 2014).

Second, the relative proportion of specialized cell types and microbial diversity and density change dramatically throughout the lower gut, in contrast to the rumen, where a more constant cell population of the SSE and luminal microbiota exists (Lavker and Motoltsy, 1970). For example, the ileum is richest in immune cells, whereas the duodenum and colon are richer in mucous cells (Kim and Ho, 2010). Additionally, the reticulo-rumen and omasum SSE are not mucosae, whereas the entire lower gut comprises loosely adherent and firmly adherent mucus layers that act as an intermediate between the lumen contents of the lower gut and the epithelial cells.

Mucus layers are predominantly composed of mucin networks (MUC2 produced by goblet cells) and other host-defense molecules produced by goblet cells, Paneth cells, and absorptive enterocytes (Kim and Ho, 2010). Microbes can be found on the outer loosely adherent mucus layer and, in rare cases, the firmly adherent mucus layer that typically contains IgA (Gallo and Hooper, 2012). This allows an extra layer of protection between the microbiota and the host. In monogastrics, the mucus layer is thinnest in the duodenum and thickest in the colon (Atuma et al., 2001), where the microbial population has the highest density and diversity (Kim and Ho, 2010). Considering the importance of mucus to gastrointestinal function, it is surprising that mucus characteristics and thickness have not been described for ruminant intestines in physiological studies as they have in monogastric CE (Atuma et al., 2001). Greater attention to mucus function in ruminants is required to properly investigate barrier function and epithelialattached microbes.

Similar to the SSE, the CE cells are joined by tight junctions, adherent junctions, and desmosomes (Turner, 2009). The submucosa lies beneath the mucosa and contains arterials and venules, as well as immune cells such as dendritic cells and lymphocytes. The submucosa is structurally diverse depending on the region of the lower gut. For example, Brunner's glands or mucus pits line the duodenum, and Peyer's patches, which

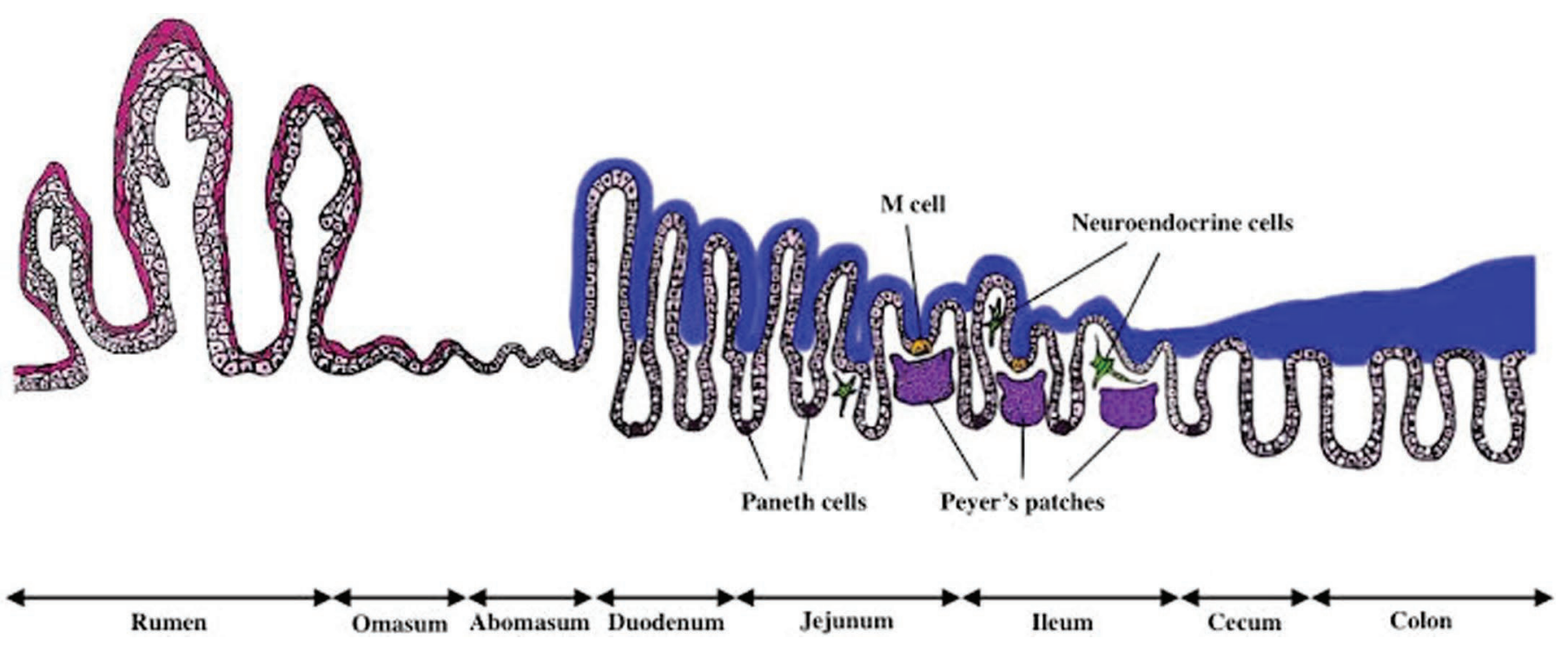

Figure 2. The diverse epithelial structure (stratified squamous epithelium and columnar epithelium), cell types (Paneth, M, and neuroendocrine cells) and mucus layer (blue) of gastrointestinal tract of ruminants. 
play an important role in immunological function, line the ileum, which further adds to the contrasts between the rumen and the lower gut (Figure 2).

\section{KEY OPPORTUNITIES RELATED TO EPITHELIAL FUNCTION}

Several key phases and challenges in dairy production can affect both GE function and economic profitability, including preweaning, weaning, the transition to highly fermentable diets, and heat stress. A common factor among all production phases and environmental challenges associated with compromised GE function is low feed intake. Recent research has demonstrated that low feed intake alone can compromise GE barrier function (Zhang et al., 2013). Because Baumgard and Rhoads (2013) provided a recent review of the effects of heat stress on metabolism and energetics, the current paper excludes the impact of heat stress on GE function.

\section{Preweaning}

The preweaned calf is the most at-risk population of cattle on the farm for GE malfunction, with digestive disorders and diseases (primarily from scours) resulting in morbidity and mortality rates above $50 \%$ and $10 \%$, respectively (USDA, 2007). In a recent survey in Canada and the United States, it was determined that $23 \%$ of dairy calves are treated for diarrhea with antibiotics during the preweaning phase (Windeyer et al., 2014). Calf health has recently been shown to affect longevity, as calves treated with antibiotics during the preweaning period are known to produce less milk in their lifetimes (Soberon et al., 2012). Establishing a stable commensal microbiota and promoting development of the GE may aid in the prevention of gastrointestinal infections and improve overall gut barrier function, resulting in improvements in efficiency, food safety, and animal welfare.

The dairy calf's GIT undergoes significant in utero development and much of the architecture and structural capacities have been set before birth (Warner et al., 1965), yet maternal and epigenetic factors are not known. From a microbiological standpoint, the GIT is considered to be devoid of live microorganisms before birth. This fact, however, is currently being questioned for monogastrics (Stout et al., 2013). Bacteria from the maternal GIT have been detected and isolated in umbilical cord blood, amniotic fluid, meconium, and placental and fetal membranes without any clinical evidence of infection or inflammation in the mother-infant pair (Jiménez et al., 2005). Maternal dendritic cells in Peyer's patches may play a role in bacterial uptake into the placenta and milk and subsequent transfer to the fetus (Thum et al., 2012; Aagaard et al., 2014). In ruminants, it is not known whether this situation also exists given the architecture of the placentome, but if so, maternal nutrition and the gastrointestinal microbiome would be important factors in determining not only gut structure, but also gut microbiota of the offspring. At birth, the inoculation of the calf's GIT may arise from the vaginal canal, fecal material, skin, and saliva. Most dairy calves are immediately removed from their dam after birth to minimize the risk of disease, which affects calf behavior (Ventura et al., 2013). However, it is not known whether limited exposure to mature dairy cows affects gut physiology, growth, and health during the early stages of life. It is well documented in humans that maternal contact and exchange of microbes of the gut is an essential part of health and development in neonates (Penders et al., 2007). It is possible that this exchange of microbiota between the dam and calf is necessary to establish a balanced microbiota, which requires more attention in future research.

After birth, the first meals are suckled, stimulating the esophageal groove to shunt colostrum and milk to the abomasum instead of the rumen, thereby creating the necessary acidic environment to initiate digestion and absorption in the lower gut (Baldwin et al., 2004b). In the first hours of life, the gut of a newborn calf is permeable to large molecules, such as IgG, before the cessation of macromolecule absorption from the lumen to blood (Taschuk and Griebel, 2012). Termination or closure of intestinal permeability to the immunoglobulins of colostrum is thought to occur spontaneously with age at a progressively increased rate after $12 \mathrm{~h}$ postpartum (Godden, 2008). Feeding colostrum shortly after birth results in earlier cessation of absorption, yet the amount of colostrum fed has no influence on closure (Taschuk and Griebel, 2012). It is speculated that the exposure to specific bacteria (Lactobacillus) may be one of the mechanisms that control cell junctions in calves, but the precise mechanisms of gut closure remain unknown.

The focus of colostrum research over the past 3 decades has been on the passive transfer of $\operatorname{IgG}$ in colostrum, with very little attention devoted to investigating other bioactives that could affect gut microbiota and growth (Blum and Hammon, 2000). Colostrum and milk have often been described as the complete prebiotic, as they contain one of the largest collections of bioactive proteins, carbohydrates, and fatty acids (Mills et al., 2011). In particular, colostrum harbors a large number of growth factors, including IGF-I, IGF-II, insulin, and epidermal growth factor-all of which directly affect gut growth signaling pathways (Roffler et al., 2003). For example, supplementing milk with IGF-1 or increasing the duration of colostrum feeding increases epithelial 
cell proliferation in the small intestine of calves (Hammon et al., 2002). Recent research focusing on the effect of duration of colostrum feeding has uncovered growth responses in total mass, villus height, and proliferation throughout the small intestine, as well as function differences in Na-dependent glucose transport mechanisms in the duodenum (Hammon et al., 2013). With respect to potential prebiotic properties within colostrum, a study comparing pasteurized and fresh colostrum determined that pasteurized colostrum maintained higher levels of Bifidobacterium and less Escherichia coli in the calf ileum and colon during the first 12 and $24 \mathrm{~h}$ of life (Malmuthuge et al., 2015). The pasteurized colostrum did not contain viable Bifidobacterium, leading the authors to speculate that the oligosaccharides in colostrum underwent chemical changes that specifically supported Bifidobacterium growth as a result of heat treatment. Collectively, the research supports the notion that the bioactive components in colostrum that play a key role in establishing microbiota balance and gut growth in the first day and weeks of life are not yet clearly described.

With respect to the regulatory mechanisms of gastrointestinal gene expression in dairy calves, microRNA (miRNA) sequences in specific gastrointestinal tissues throughout the preweaned period were characterized by Liang et al. (2014). The miRNA are a group of small ( $\sim 22$ nucleotides) endogenous RNA molecules that bind coding RNA and block translation to regulate gene expression, which may play important role in regulating rumen development (He and Hannon, 2004). Liang et al. (2014) found region-specific miRNA throughout the small intestine, the expression patterns of which changed throughout the first 6 wk of life. Interestingly, the expression changes were the most diverse during the first week of life, and many of these miRNA targeted genes involved in the immune response, suggesting that the miRNA could regulate immune function development during early life. The authors also observed relationships between the expression of miRNA and the abundance of beneficial bacteria; namely, Lactobacillus and Bifidobacterium, underlining the potential role of miRNA in cross-talk between host and gastrointestinal microbiota.

Recently, there has been a renewed interest in endocrine control of gut barrier function and growth in dairy cattle, with most of the work being performed using preweaned dairy calves. Of the numerous hormones that are produced by the calf gut, GLP-2 has received considerable attention over the last 5 yr (Connor et al., 2015). The GLP-2 hormone is produced by enteroendocrine $\mathrm{L}$ cells and by various neurons in the central nervous system (Estall and Drucker, 2006). Intestinal GLP-2 is co-secreted along with GLP-1 upon nutrient ingestion and is a stimulator of intestinal growth (Burrin et al., 2003). Treatment with GLP-2 of primary submucosal neurons isolated from rodent intestine increased expression of multiple growth factors, including IGF-1 (Connor et al., 2015). Recently, 2 studies involving calves reported that subcutaneous injections of GLP-2 during an Eimeria bovis challenge decreased oxidative tissue damage and improved epithelial integrity (Connor et al., 2013b) in the lower gut and increased the mRNA and protein expression of tight junction proteins in the small intestine (Walker et al., 2015). In the studies of Górka et al. (2009, 2011), where protected butyrate was supplemented in milk replacer, blood levels of GLP-2 and IGF-1 increased, which was associated with increased levels of proliferation and growth of both the intestine and rumen. All of these findings suggest that more targeted research is needed to determine which microbiota, nutrients, and feeding strategies stimulate the production of GLP-2 and IGF-1. Of great interest is the mechanism of communication among intestinal factors in the different compartments of the gut. Studies integrating multiple compartments of the ruminant SSE and CE are essential in understanding how a nutritional treatment can affect the entire GIT.

\section{Weaning}

Perhaps one of the most dramatic gastrointestinal transformations in the ruminant's life is the transition from functioning as a monogastric to a ruminant. Traditionally, dairy calves have been weaned early, at 1 to 3 mo of life. In many cases, the GIT is not ready for early weaning, especially if the high levels of milk being fed as the stimulus to promote ruminal development are reduced (de Passillé et al., 2011; Eckert et al., 2015). Finding optimal weaning strategies that stimulate GE development becomes increasingly important as the industry moves toward feeding elevated levels of milk, because dry feed intake preweaning needs to be maximized to decrease the risk of depressed growth rates and disease during the weaning period (Khan et al., 2011).

During weaning, calves must transition from a milkbased diet that is primarily digested in the abomasum and small intestine to one based on solid feed intake and ruminal fermentation (Baldwin et al., 2004b; Guilloteau et al., 2009). Thus, weaning not only changes the site of digestion and absorption, but also changes the nutrients available for absorption and postabsorptive metabolism (Klotz and Heitmann, 2007). Weaning occurs only months after birth and is marked by the rumen capacity increasing from 30 to $70 \%$ of the entire GIT (Warner et al., 1965). Expansion is needed 
to increase the surface area for absorption of the products of ruminal fermentation; namely, SCFA, to meet the demands for growth (Baldwin et al., 2004b). The dramatic shift in physiology and metabolism of early weaning contrasts natural weaning, which occurs gradually over many weeks when calves are left to nurse from their dams to approximately 10 mo of age (Reinhardt and Reinhardt, 1981). It is becoming common to feed more milk preweaning to accelerate growth and improve potential lifetime production (Soberon et al., 2012; Soberon and Van Amburgh, 2013). To support accelerated weight gain with elevated quantities of milk feeding, concurrent accelerated rumen and intestinal adaptation are required, including microbiological, structural, and functional changes in SSE and CE.

Structural development in the rumen is promoted by the consumption of solid feed; however, the microbiological adaptations begin at birth. As stated previously, the inoculation of the calf's rumen from the dam begins at birth from several sources: vaginal canal, fecal material, colostrum, skin, and saliva. Bacteria appear in the first day of life, especially those of aerobic or facultative anaerobic-related taxa. For instance, Proteobacteriaand Streptococcus-related sequences were substantially represented in 1- to 3-d-old calves (Jami et al., 2013; Rey et al., 2014). These primo-colonizing bacteria may play an important role in shaping the biotope for strictly anaerobic microbial populations colonizing rapidly afterward (Fonty and Chaucheyras-Durand, 2007). Bacterial diversity and species richness increase with age, with 45 to 47 genera belonging to 13 to 15 phyla being identified in 2- to 3-wk-old calves (Jami et al., 2013; Malmuthuge et al., 2014). A few genera seem to be shared among the bacterial communities found during primary stages of colonization and in mature animals, suggesting that the establishment of bacterial communities during the first days of life may imprint microbiota later in life ( $\mathrm{Li}$ et al., 2012a; Jami et al., 2013).

After the first week of life, cellulolytic bacteria and fungi are increased even though the rumen is not functional and no complex polysaccharides have been ingested (Fonty et al., 1987). The calf rumen microbiota harbors considerable functional diversity, as evidenced by the identification of more than 8,000 putative protein families (Li et al., 2012a). Notably, metagenomics studies have revealed that a great number of polysaccharide hydrolase microbial genes are present in the rumen, suggesting remarkable potential for plant carbohydrate metabolism at early stages of life ( $\mathrm{Li}$ et al., 2012a). This finding was confirmed by the measurement of fibrolytic activities in the young ruminant rumen (Rey et al., 2012; Jiao et al., 2015). In the young ruminant, the establishment of Archaea methanogens occurs simultaneously with that of cellulolytic bacteria (Morvan et al., 1994), and Methanobrevibacter sp. are found as a dominant genus (Gagen et al., 2012; Zhou et al., 2014). Colonization of the rumen wall by epimural bacteria is also age-related. In goat kids, Jiao et al. (2015) noted that on the day of birth, measurements of the phylum Proteobacteria far exceeded other phyla $(90.13 \%)$, with the majority belonging to the genus Escherichia; this finding ultimately confirmed earlier studies using cultural methods (Rieu et al., 1989). This microbiota might be derived from that of the mother's vagina, skin, colostrum, or environment, and may have a particular importance in scavenging oxygen diffusing from the capillary network, thereby creating ecological conditions suitable for the establishment of anaerobic communities. Ciliate protozoa are the last community to become established in the rumen. They are detected from 2 to 3 wk of age, with Entodinium spp. being first to appear (Abecia et al., 2014). Studies using culturing methods have indicated that the rumen microbial ecosystem is stabilized after 2 mo of life (Fonty et al., 1987); however, in studies using $16 \mathrm{~S}$ rRNA gene sequencing methods, the mature bacterial arrangement was not detected before 6 mo, when Bacteroidetes, Firmicutes, and Proteobacteria were among the dominant phyla (Jami et al., 2013).

Although rumen development and microbial colonization have attracted a lot of attention recently, a basic understanding of ruminal morphology and physiology remains elusive. Rumen histomorphogenesis starts early during fetal life, at around 30 to $35 \mathrm{~d}$ of gestation depending on ruminant species, and stratification of the rumen epithelium starts after $50 \mathrm{~d}$, which coincides with the appearance of ruminal pillars and papillae (García et al., 2012). It has been shown that encouraging solid feed intake by restricting milk access increases the size of the rumen as well as the dimensions of rumen papillae (Khan et al., 2011). Most studies report height and width of rumen papillae as an estimate of rumen epithelium growth (Steele et al., 2014). As shown recently using micro-computed tomography methods, increased papillae height and width do not necessarily result in increased surface area, as papillae density must also be considered (Steele et al., 2014).

Of the SCFA, butyrate has been reported to be a potent stimulator of ruminal epithelial proliferation in vivo (Sakata and Tamate, 1978), and recent findings suggest the same in the lower gut (Górka et al., 2011; Kowalski et al., 2015). The molecular mechanisms behind this stimulated development, however, are poorly understood. To investigate the active transcription factors that may be controlling ruminal SSE adaptations during weaning, a series of microarray experiments was conducted comparing preweaning rumen tissue with tis- 
sues from weaned calves consuming a hay or concentrate diet (Connor et al., 2013a, 2014). These studies showed that the expression of transforming growth factor $\beta 1$ ( TGF 1 1) partially controlled the expression of multiple gene families involved in cellular differentiation and epithelial development. A family of DNA transcription factors, termed nuclear protein receptors, are known to bind to metabolites (especially fatty acids) in the cytoplasm, and affect the transcription of many genes. In the same study by Connor et al. (2014) 2 nuclear receptors, peroxisome proliferator-activated receptor $($ PPAR $) \alpha$ and estrogen related receptor- $\alpha$ (ESRR $\alpha)$, were responsive to weaning in rumen tissue. In a study comparing elevated and conventional feeding schemes before (wk 5) and after weaning (wk 10), it was also determined that PPAR $\alpha$ and PPAR $\delta$ were activated transcription factors (Naeem et al., 2014). This work corresponds with research in mature dairy cattle, in which genes associated with fatty acid metabolism and cholesterol biosynthesis (PPAR) were also found to be responsive in the rumen epithelium of cows transitioned to a highly fermentable diet (Steele et al., 2011a).

As previously described, miRNA may play a role in gene expression during the preweaning and weaning periods (Liang et al., 2014). The study by Liang et al. (2014) identified miR-205 as being highly expressed in the rumen ( $>60 \%$ of all miRNA sequences) and as a potential regulator of cell proliferation and the development of ruminal SSE during early life. Interestingly, Liang et al. (2014) proposed that miRNA expression might influence bacterial populations in the rumen due to the observed association between the expression of particular miRNA (e.g., miR-129) and the total bacterial population in the rumen. Elucidating the regulatory mechanisms will be a challenge considering the confounding effects of the microbial population density and diversity, changes in nutrient intake and hence an increase in rumen fermentation, and calf age. However, understanding the driving factors could lead to development of novel feed additives that stimulate GE development and improve the success of weaning programs, even with elevated milk feeding protocols.

Weaning-related research has typically revolved around the rumen and maximizing solid feed intake. A focus on the ruminal environment neglects the effect of how this shift in nutrients and microbiota influence the lower gut. With regard to gastrointestinal adaptation, one aspect that is often overlooked is barrier function. Gastrointestinal tract barrier function involves secretory processes (e.g., alkaline phosphatase, secretory $\operatorname{IgG}$, defensins), the innate immune response, and permeability of the GIT (Peterson and Artis, 2014). Malmuthuge et al. (2013) reported that feeding starter in combination with milk replacer near weaning tended to increase the mRNA expression of toll-like receptor (TLR)-3, TLR-4, TLR-5, and $\beta$-defensin and significantly increased $T L R-6$ and peptidoglycan recognition protein 1 (PGRP-1). These data represent some of the first work characterizing the innate immune response in calves at weaning and suggest potential for greater detection of microbial-associated molecular patterns and control of the microbiome. However, it should be noted that functionality might not be correlated with mRNA expression.

More recently, Wood et al. (2015) demonstrated that gastrointestinal permeability decreases (suggesting improved barrier function) as calves age from 17 to $42 \mathrm{~d}$. However, the authors noted that weaning alters this age-dependent process. Wood et al. (2015) characterized regional responses for permeability and innate immune responses and demonstrated that the rumen, duodenum, and jejunum are regions at the greatest risk of impaired barrier function. This differs from Malmuthuge et al. (2013), where the jejunum, ileum, and cecum were implicated as regions with reduced barrier function based on mRNA abundance of claudin 4 . Research in infants and piglets has clearly documented inflammation and morphological changes of the intestinal tract during weaning (Pié et al., 2004). The same can be expected to occur in ruminants, as the levels of starch are equally high. An increase in inflammatory markers has been shown during the weaning of dairy calves (Kim et al., 2011). It may be that calves suffer temporarily from hindgut acidosis, because they exhibit elevated fecal starch levels during weaning (Eckert et al., 2015). Greater investigation of the lower gut microbiological, structural, and functional changes and how these changes contribute to weaning stress is a logical next step in research.

\section{Transition to Highly Fermentable Diets}

Meeting the net energy and metabolizable protein requirements of high-producing dairy cows requires the use of highly fermentable diets. An abrupt transition to a highly fermentable diet causes the rate of SCFA production by ruminal fermentation to exceed the rate of ruminal buffering, passage, and especially absorption, depressing $\mathrm{pH}$ below 5.6 for hours a day, indicative of the digestive disorder subacute ruminal acidosis (SARA). The transition from low energy to highly fermentable diets, such as during the transition from the dry period to lactation, is believed to predispose cattle to SARA (Plaizier et al., 2008). It has been estimated that SARA occurs in $20 \%$ of lactating dairy cattle and is most prevalent in early lactation (Penner et al., 2007). The disorder is associated with depressed feed intake, production, decreased milk fat and milk 
fat yield, and more recently whole-animal inflammation (Plaizier et al., 2008). Decreasing barrier dysfunction and increasing growth during times when cows are at risk of SARA may provide an opportunity to decrease inflammation and improve the energy balance of dairy cattle. The adaptations of the rumen microbiota and rumen epithelium during the transition to rapidly fermentable diets have been previously summarized in reviews by Nagaraja and Titgemeyer (2007) and Penner et al. (2011). This section of the review will further develop these concepts with recent literature and new data related to the lower gut.

Unlike acute lactic acidosis, SARA is a more chronic condition, as lactic acid-consuming bacteria in the rumen, such as Megasphaera elsdenii, are able to convert lactic acid to propionic acid (Stone, 2004). However, in both SARA and acute ruminal acidosis, ruminal LPS concentrations are elevated. Lipopolysaccharide is a cell wall component of gram-negative bacteria and a well-known endotoxin and potent stimulator of the immune system (Khafipour et al., 2009). Although LPS has been the focal point, it should be noted that other potential microbial products can induce inflammatory responses, such as lipoteichoic acid, flagellin, histamine, and other microbial fragments. The increase in ruminal LPS and other microbial products during acidosis may translocate through the ruminal SSE as it has been determined that low $\mathrm{pH}$ results in increased paracellular permeability (Penner et al., 2010; Wilson et al., 2012). An in vivo study documented a decrease in ruminal epithelial thickness and an increase in SSE lesions during SARA (Steele et al., 2011b). Furthermore, downregulation of tight junction genes (occludins and claudins) was noted in the ruminal SSE of goats transitioned to a high-grain diet (Liu et al., 2013). Moreover, SARA is associated with elevated levels of acute phase proteins such as serum amyloid A and haptoglobin (Plaizier et al., 2008), indicative of systemic inflammation originating from a leaky ruminal SSE.

The notion that compromised ruminal SSE barrier function is primarily responsible for inflammation during SARA was questioned in a study by $\mathrm{Li}$ et al. (2012b), in which ruminal acidosis was induced by grain or alfalfa pellets. Both treatments depressed $\mathrm{pH}$, causing ruminal acidosis; however, acute phase proteins (serum amyloid A and haptoglobin) were only elevated in the blood stream in the high-grain diet. This was hypothesized based on elevated starch and LPS due to the turnover of LPS levels in the fecal digesta of cows induced with acidosis by a high-grain diet. Recently, Tao et al. (2014a,b) characterized the changes to the cecum and colon in goats that were transitioned to a high-grain diet. In that experiment, the high-grain challenge decreased the expression of tight junction and increased the apoptotic cell numbers in both tissues. These results align with hypotheses related to dietary transition of the lower gut of the calf during weaning (Wood et al., 2015), in which permeability of the gut was shown to increase during weaning (provision of rapidly fermentable concentrates). Based on the structure, the multilayered ruminal SSE may be less permeable to allow the transmigration of endotoxins and bacteria compared with the single layer of the $\mathrm{CE}$ in the lower gut (Figure 1; Metzler-Zebeli et al., 2013) and, based on permeability measurements, the duodenum may be a region with particularly high paracellular permeability (Penner et al., 2014). However, further exploration is needed to determine the extent of lower gut disruption to barrier function during this rapid shift to diets rich in rapidly fermentable carbohydrates.

Although barrier function of the dairy cow GE is important, opportunities may exist to improve energy balance and gastrointestinal function by stimulating gastrointestinal growth either before or in early lactation. For example, the rumen mass increases by $55 \%$, as a percentage of empty BW, from 14 to 240 DIM (Baldwin et al., 2004a). Moreover, small intestine mass increases by $38 \%$ from 14 to 90 DIM (Baldwin et al., 2004a). Because the increased surface area would increase the amount of SCFA absorption, it may elevate ruminal $\mathrm{pH}$ and decrease the incidence of ruminal acidosis. Although there is an energy cost to increasing the surface area of the gut, the delayed growth of the rumen limits the uptake capacity, thus reducing the overall energy balance (Cant et al., 1996). Interestingly, specific nutrients such as rumen-protected butyrate are thought to increase ruminal growth when fed before lactation as a means to prime the rumen of the cow for lactation (Kowalski et al., 2015). The transcriptome of the ruminal SSE during the transition period has been characterized and $I G F-1$, growth hormone $(G H)$, epidermal growth factor $(E G F)$, and $T G F \beta 1$ were found to be responsive control mechanisms of cellular differentiation and development between the dry period and the first week of lactation (Steele et al., 2015). Understanding which pathways control adaptations of the GE could provide insight into how to stimulate growth earlier in lactation to improve energy balance. The same may be possible for the lower gut during early lactation but it has received no attention.

\section{FUTURE CONSIDERATION FOR RESEARCH}

In recent years, substantial advancements have been made in the characterization of the GE microbiome and transcriptome of dairy calves and cows during times of gastrointestinal development and dysfunction. Many similarities exist between gut-related challenges, such 
as during weaning and transition to rapidly fermentable diets, and recognizing the similarities will maximize the utilization of data to improve gut function. This could lead to the discovery of bioactive nutrients and feeding schemes that benefit GE function in multiple applications.

Another key element that could support progress is the implementation of high-throughput genomic data interrelated with gastrointestinal function measurements. Functional measurements of the GIT in dairy calves and cows include epithelial permeability, epithelial proliferation, morphology, histology, gastric emptying and passage, nutrient digestion, transport, and metabolism. Such vast and sophisticated measurements related to gut function would improve the breadth of knowledge, especially when interrelated with the new high-throughput molecular-based research.

We are now beginning to realize that the effect of a diet on its host is dependent on the microbiota, because when dietary components are consumed they are rapidly converted to microbial metabolites (Turnbaugh et al., 2006). The ways in which different members of the microbial community contribute to the metabolite pool of the lumen provides an important mechanism through which diet modulates GE function. The classic examples are butyrogenic diets that support Bifidobacterium populations or substrate for butyrate synthesis (Hamer et al., 2008). Butyrate is a well-known nutrient that is purported to elicit GE growth responses in both dairy cows and preweaned calves (Górka et al., 2011; Kowalski et al., 2015). Many metabolites, such as butyrate, elicit responses in the gut or host through nutrient sensors in the GE that work in conjunction with hormonal and neural signaling to adapt the GIT to the elevated pool of metabolites (Furness et al., 2013). Thus, as the adaptation to a metabolite in one compartment of the GIT can affect several compartments, it is of great value to investigate multiple regions of the GIT when examining the effects of nutrients, hormones, or neurons on GE function.

To uncover the full extent of a dietary intervention on gastrointestinal function, the number of GIT compartments sampled and analyzed in an experiment should be maximized. However, there seems to be some reluctance to conduct such holistic research, due at least in part to the complexity of the lower gut and the variability of cell types among regions. Ideally, all regions of the gut should be sampled simultaneously during an experiment; however, issues of practicality and budgetary constraints often impede such research. Beyond these impediments, there is a notable lack of consistency in sampling techniques and protocols among research groups. For example, the majority of scientific questions are being directed toward the GE; however, the mucosa, submucosa, muscularis, and serosa are all being effectively used in most functional genomic studies (Steele et al., 2013). Improved communication among research groups to standardize methods of GE dissection and preservation before sample analysis would ultimately improve the scope and efficacy of future research.

Key mechanisms of interest for future research include the regulation of GE barrier function and proliferation. In ruminants, we are in the beginning stages of characterizing barrier function and its regulation. Barrier function has been investigated in the ruminant by probing the mRNA and protein expression of tight junction genes during development (Malmuthuge et al., 2014) and during feeding of high-grain diets (Steele et al., 2011b; Liu et al., 2013). Hundreds of mechanisms - stemming from microbiota, luminal microbiota and endotoxins, and metabolites - that affect tight junction signaling have emerged in medical research, yet these areas remain poorly defined in the cow and calf. The area of study requiring immediate attention is the mucus layers of the lower gut, as it remains an area entirely unexplored. The importance of the mucus layers should not go unrecognized, as they have been shown to play a key role in protecting and mediating microbiota between the $\mathrm{CE}$ and lumen (Kim and Ho, 2010).

The benefit of increased GE proliferation, which leads to an increase in uptake capacity, typically outweighs the added energy expenditure. However, in the growing animal, there is a point at which the allocation of more metabolizable energy to the intestine to improve capacity becomes detrimental to the energy utilization and growth of the animal (Cant et al., 1996). There also seems to be a maximum organ size that constrains the ability of the intestine to grow, even in the presence of sufficient energy. Growth stimulators and inhibitors, then, are candidates to manipulate efficiency of absorption. Among pathways that alter the GIT, the somatotropic axis, which encompasses IGF and growth hormone, is thought to play a role in GE proliferation (Steele et al., 2011b, 2012a,b, 2015). Exciting progress has been made in the characterization of the pleiotropic effects of gastric hormones, in particular GLP-2. Hormones such as GLP-2 are of great interest because their responses to barrier function have been well characterized and shown to increase blood flow (Connor et al., 2015). The amount of luminal uptake of nutrients can be maximized if epithelial proliferation to increase surface area occurs together with increased blood flow (Cant et al., 1996). Identifying the specific nutrients or feeding schemes that stimulate gastric hormones, such 
as GLP-2, with pleiotropic actions may be of significant benefit to dairy cow and calf health and production and should be an area of continued focus.

\section{CONCLUSIONS}

Renewed interest in the GE has occurred in dairy research and the dairy industry, leading to expanded adoption of nutritional additives (e.g., SCFA, probiotics, prebiotics). The term "gut health" has become a buzzword in dairy nutrition, yet it is loosely defined, even scientifically, so careful consideration of the gut health-promoting action of a particular nutrient or feeding strategy is important. For instance, there may be circumstances where increased or decreased GE barrier function does not promote health and impedes overall animal performance. In any case, great potential exists to understand and improve applications related to GE ailments in preweaned calves, during weaning, and during the transition to rapidly fermentable diets. Combining in vivo measurements of gut function with high-throughput molecular data will enable rapid progress in this emerging field. Collaboration and communication among research groups to achieve more consistency in research methods will also enhance the body of knowledge regarding ruminal and lower gut function and development.

\section{ACKNOWLEDGMENTS}

The authors thank the support of the Natural Science and Engineering Research Council (Ottawa, ON, Canada) and Alberta Milk (Edmonton, AB, Canada). We also appreciate the dedication and patience of Jade Pyo for her assistance with the illustrations in this review.

\section{REFERENCES}

Aagaard, K., J. Ma, K. M. Antony, R. Ganu, J. Petrosino, and J. Versalovic. 2014. The placenta harbors a unique microbiome. Sci. Transl. Med. 6:237ra65.

Abecia, L., K. E. Waddams, G. Martinez-Fernandez, A. I. MartinGaricia, E. Ramos-Morales, C. J. Newbold, and D. R. Yanez-Ruiz. 2014. An anitmethogenic nutritional intervention in early life of ruminants modifies ruminal colonization by Archaea. Archaea 2014:841463. http://dx.doi.org/10.1155/2014/841463.

Aschenbach, J. R., G. B. Penner, F. Stumpff, and G. Gäbel. 2011. Role of fermentation acid absorption in the regulation of $\mathrm{pH}$. J. Anim. Sci. 89:1092-1107.

Atuma, C., V. Strugala, A. Allen, and L. Holm. 2001. The adherent gastrointestinal mucus gel layer thickness and physical state in vivo. Am. J. Physiol. Gastrointest. Liver Physiol. 280:G922-G929.

Baldwin, R. L., VI, K. R. McLeod, and A. V. Capuco. 2004a. Visceral tissue growth and proliferation during the bovine lactation cycle. J. Dairy Sci. 87:2977-2986.

Baldwin, R. L., VI, K. R. McLeod, J. L. Klotz, and R. N. Heitmann. 2004b. Rumen development, intestinal growth and hepatic me- tabolism in the pre- and postweaning ruminant. J. Dairy Sci. 87(E. Suppl.):E55-E65.

Baldwin, R. L., VI, S. Wu, W. Li, C. Li, B. J. Bequette, and R. W. Li. 2012. Quantification of transcriptome responses of the rumen epithelium to butyrate infusion using RNA-seq technology. Gene Regul. Syst. Bio. 6:67-80.

Baumgard, L. H., and R. P. Rhoads Jr.. 2013. Effects of heat stress on postabsorptive metabolism and energetics. Annu. Rev. Anim. Biosci. 1:311-337.

Blum, J. W., and H. Hammon. 2000. Colostrum effects on the gastrointestinal tract, and on nutritional, endocrine and metabolic parameters in neonatal calves. Livest. Prod. Sci. 66:151-159.

Burrin, D. G., B. Stoll, and X. Guan. 2003. Glucagon-like peptide 2 function in domestic animals. Domest. Anim. Endocrinol. 24:103122.

Cant, J. P., B. W. McBride, and W. J. Croom Jr.. 1996. The regulation of intestinal metabolism and its impact on whole animal energetics. J. Anim. Sci. 74:2541-2553.

Connor, E. E., R. L. Baldwin VI, M. P. Walker, S. E. Ellis, C. Li, S. Kahl, H. Chung, and R. W. Li. 2014. Transcriptional regulators transforming growth factor- $\beta 1$ and estrogen-related receptor- $\alpha$ identified as putative mediators of calf rumen epithelial tissue development and function during weaning. J. Dairy Sci. 97:41934207

Connor, E. E., C. M. Evock-Clover, M. P. Walker, T. H. Elsasser, and S. Kahl. 2015. Comparative physiology of glucagon-like peptide-2: Implications and applications for production and health of ruminants. J. Anim. Sci. 93:492-501.

Connor, E. E., R. L. Baldwin VI, C. Li, R. W. Li, and H. Chung 2013a. Gene expression in bovine rumen epithelium during weaning identifies molecular regulators of rumen development and growth. Funct. Integr. Genomics. 13:133-142.

Connor, E. E., S. Kahl, T. H. Elsasser, R. L. Baldwin VI, R. Fayer, M. Santin-Duran, G. L. Sample, and C. M. Evock-Clover. 2013b. Glucagon-like peptide 2 therapy reduces negative effects of diarrhea on calf gut. J. Dairy Sci. 96:1793-1802.

de Passillé, A. M., T. F. Borderas, and J. Rushen. 2011. Weaning age of calves fed a high milk allowance by automated feeders: Effects on feed, water, and energy intake, behavioral signs of hunger, and weight gains. J. Dairy Sci. 94:1401-1408.

Eckert, E., H. E. Brown, K. E. Leslie, T. J. DeVries, and M. A. Steele. 2015. Weaning age affects growth, feed intake, gastrointestinal development, and behavior in Holstein calves fed an elevated plane of nutrition during the preening stage. J. Dairy Sci. 98:6315-6326.

Estall, J. L., and D. J. Drucker. 2006. Glucagon-like peptide-2. Annu. Rev. Nutr. 26:391-411.

Fonty, G., and F. Chaucheyras-Durand. 2007. Les écosystèmes digestifs. Pages 71-126 in Les Communautes microbiennes du tube digestif des mammiferes: Diversite et structure. Tec\&Doc Lavoisier, Paris, France.

Fonty, G., P. Gouet, J. Jouany, and J. Senaud. 1987. Establishment of the microflora and anaerobic fungi in the rumen of lambs. J. Gen. Microbiol. 133:1835-1843.

Furness, J. B., L. R. Rivera, H. J. Cho, D. M. Bravo, and B. Callaghan. 2013. The gut as a sensory organ. Nat. Rev. Gastroenterol. Hepatol. 10:729-740. http://dx.doi.org/10.1038/nrgastro.2013.180.

Gäbel, G., J. R. Aschenbach, and F. Müller. 2002. Transfer of energy substrates across the ruminal epithelium: Implications and limitations. Anim. Health Res. Rev. 3:15-30.

Gagen, E. J., P. Mosoni, S. E. Denman, R. Al Jassim, C. S. McSweeney, and E. Forano. 2012. Methanogen colonisation does not significantly alter acetogen diversity in lambs isolated $17 \mathrm{~h}$ after birth and raised aseptically. Microb. Ecol. 64:628-640.

Gallo, R. L., and L. V. Hooper. 2012. Epithelial antimicrobial defence of the skin and intestine. Nat. Rev. Immunol. 12:503-516.

García, A., J. Masot, A. Franco, A. Gázquez, and E. Redondo. 2012. Histomorphometric and immunohistochemical study of the goat rumen during prenatal development. Anat. Rec. (Hoboken) 295:776-785.

Godden, S. 2008. Colostrum management for dairy calves. Vet. Clin. North Am. Food Anim. Pract. 24:19-39. 
Górka, P., Z. M. Kowalski, P. Pietrzak, A. Kotunia, W. Jagusiak, J. J. Holst, P. Guilloteau, and R. Zabielski. 2011. Effect of method of delivery of sodium butyrate on rumen development in newborn calves. J. Dairy Sci. 94:5578-5588.

Górka, P., Z. M. Kowalski, P. Pietrzak, A. Kotunia, R. Kiljanczyk, J. Flaga, J. J. Holst, P. Guilloteau, and R. Zabielski. 2009. Effect of sodium butyrate supplementation in milk replacer and started diet on rumen development in calves. J. Physiol. Pharmacol. 60:47-53.

Graham, C., and N. L. Simmons. 2005. Functional organization of the bovine rumen epithelium. Am. J. Physiol. Regul. Integr. Comp. Physiol. 288:R173-R181.

Guilloteau, P., O. Zabielski, and J. W. Blum. 2009. Gastrointestinal tract and digestion in the young ruminant: Ontogenesis, adaptions, consequences and manipulations. J. Physiol. Pharmacol. 60:37-46.

Hamer, H. M., D. Jonkers, K. Venema, S. Vanhoutvin, F. J. Troost, and R. J. Brummer. 2008. Review article: the role of butyrate on colonic function. Aliment. Pharmacol. Ther. 27:104-119.

Hammon, H. M., G. Schiessler, A. Nussbaum, and J. W. Blum. 2002. Feed intake patterns, growth performance, and metabolic and endocrine traits fed unlimited amounts of colostrum and milk by automate, starting in the neonatal period. J. Dairy Sci. 85:33523362.

Hammon, H. M., J. Steinhoff-Wagner, J. Flor, U. Schönhusen, and C. C. Metges. 2013. Lactation Biology Symposium: Role of colostrum and colostrum components on glucose metabolism in neonatal calves. J. Anim. Sci. 91:685-695.

He, L., and G. Hannon. 2004. MicroRNAs: Small RNAs with a big role in gene regulation. Nat. Rev. Genet. 5:522-531.

Jami, E., A. Israel, A. Kotser, and I. Mizrahi. 2013. Exploring the bovine rumen bacterial community from birth to adulthood. ISME J. $7: 1069-1079$.

Jiao, J., J. Huang, C. Zhou, and Z. Tan. 2015. Taxonomic identification of ruminal epithelial bacterial diversity during rumen development in goats. Appl. Environ. Microbiol. 81:3502-3509.

Jiménez, E., L. Fernandez, M. L. Marin, R. Martin, J. M. Odriozola, C. Nueno-Palop, A. Narbad, M. Olivares, J. Xaus, and J. M. Rodriguez. 2005. Insolation of commensal bacteria from umbilical cord blood of health neonates by caesarean section. Curr. Microbiol. 51:270-274.

Khafipour, E., S. Li, J. C. Plaizier, and D. O. Krause. 2009. Rumen microbiome composition determined using two nutritional models of subacute ruminal acidosis. Appl. Environ. Microbiol. 75:7115-7124.

Khan, M. A., D. M. Weary, and M. A. G. von Keyserlingk. 2011. Invited review: Effects of milk ration on solid feed intake, weaning, and performance in dairy heifers. J. Dairy Sci. 94:1071-1081.

Kim, M. H., J. Yang, S. D. Upadhaya, H. Lee, C. Yun, and J. K. Ha. 2011. The stress of weaning influences serum levels of acute-phase proteins, iron-binding proteins, inflammatory cytokines, cortisol, and leukocyte subsets in Holstein calves. J. Vet. Sci. 12:151-157.

Kim, Y. S., and S. B. Ho. 2010. Intestinal goblet cells and mucins in health and disease: Recent insights and progress. Curr. Gastroenterol. Rep. 12:319-330.

Klotz, J. L., and R. N. Heitmann. 2007. Changes in net portal nutrient flux in response to weaning transition and ionophore supplementation in dairy calves. J. Dairy Sci. 90:1326-1339.

Kowalski, Z. M., P. Gorka, J. Flaga, A. Barteczko, K. Burakowska, J. Oprzadek, and R. Zabielski. 2015. Effect of microencapsulated sodium butyrate in the close-up diet on performance of dairy cows in the early lactation period. J. Dairy Sci. 98:3284-3291.

Lavker, R. M., and A. G. Matoltsy. 1970. The fate of cell organelles and differentiation products in ruminal epithelium. J. Cell Biol. 44:501-512.

Li, R. W., E. E. Connor, C. Li, R. L. Baldwin IV, and M. E. Sparks. 2012a. Characterization of rumen microbiota of pre-ruminant calves using metagenomic tools. Environ. Microbiol. 14:129-139.

Li, S., E. Khafipour, D. O. Krause, A. Kroeker, J. C. RodriguezLecompte, G. N. Gozho, and J. C. Plaizier. 2012b. Effects of subacute ruminal acidosis challenges on fermentation and endotoxins in the rumen and hindgut of dairy cows. J. Dairy Sci. 95:294-303.
Liang, G., N. Malmuthuge, T. B. McFadden, H. Bao, P. H. Griebel, P. Stothard, and L. L. Guan. 2014. Potential regulatory role of microRNAs in the development of bovine gastrointestinal tract during early life. PLoS ONE 9:e92592.

Liu, J. H., T. T. Xu, Y. J. Liu, W. Y. Zhu, and S. Y. Mao. 2013 A high-grain diet causes massive disruption of ruminal epithelial tight junctions in goats. Am. J. Physiol. Regul. Integr. Comp. Physiol. 305:R232-R241.

Malmuthuge, N., Y. Chen, G. Liang, L. A. Goonewardene, and L. L. Guan. 2015. Heat-treated colostrum feeding promotes beneficial bacteria colonization in the small intestine of neonatal calves. J. Dairy Sci. 98:8044-8053.

Malmuthuge, N., P. J. Griebel, and L. L. Guan. 2014. Taxonomic identification of commensal bacteria associated with the mucosa and digesta throughout the gastrointestinal tracts of preweaned calves. Appl. Environ. Microbiol. 80:2021-2028.

Malmuthuge, N., M. Li, L. A. Goonewardene, M. Oba, and L. L. Guan. 2013. Effect of calf starter feeding on gut microbial diversity and expression of genes involved in host immune responses and tight junctions in dairy calves during weaning transition. J. Dairy Sci. 96:3189-3200.

Metzler-Zebeli, B. U., S. Schmitz-Esser, F. Klevenhusen, L. Podstatzky-Lichtenstein, M. Wagner, and Q. Zebeli. 2013. Grain-rich diets differently alter ruminal and colonic abundance of microbial populations and lipopolysaccharide in goats. Anaerobe 20:65-73.

Mills, S., R. P. Ross, C. Hill, G. F. Fitzgerald, and C. Stanton. 2011. Milk intelligence: Mining milk for bioactive substances associated with human health. Int. Dairy J. 21:377-401.

Morvan, B., J. Doré, F. Rieu-Lesme, L. Foucat, G. Fonty, and P. Gouet. 1994. Establishment of hydrogen-utilizing bacteria in the rumen of the newborn lamb. FEMS Microbiol. Lett. 117:249-256.

Naeem, A., J. K. Drackley, J. Stamey Lanier, R. E. Everts, S. L. Rodriguez-Zas, and J. J. Loor. 2014. Ruminal epithelium transcriptome dynamics in response to plane of nutrition and age in young Holstein calves. Funct. Integr. Genomics 14:261-273.

Nagaraja, T. J., and E. C. Titgemeyer. 2007. Ruminal acidosis in beef cattle: The current microbiological and nutritional outlook. J. Dairy Sci. 90(E. Suppl.):E17-E38.

Penders, J., E. E. Stobberingh, P. A. van den Brandt, and C. Thijs. 2007. The role of the intestinal microbiota in the development of atopic disorders. Allergy 62:1223-1236.

Penner, G. B., J. R. Aschenbach, K. Wood, M. E. Walpole, R. Kanafany-Guzman, S. Hendrick, and J. Campbell. 2014. Characterizing barrier function among regions of the gastrointestinal tract in Holstein steers. Anim. Prod. Sci. 54:1282-1287.

Penner, G. B., K. A. Beauchemin, and T. Mutsvangwa. 2007. Severity of ruminal acidosis in primiparous Holstein cows during the periparturient period. J. Dairy Sci. 90:365-375.

Penner, G. B., M. Oba, G. Gaebel, and J. R. Aschenbach. 2010. A single mild episode of subacute ruminal acidosis does not affect ruminal barrier function in the short term. J. Dairy Sci. 93:4838-4845.

Penner, G. B., M. A. Steele, J. R. Aschenbach, and B. W. McBride. 2011. Ruminant Nutrition Symposium: Molecular adaptation of ruminal epithelia to highly fermentable diets. J. Anim. Sci. 89:1108-1119.

Peterson, L. W., and D. Artis. 2014. Intestinal epithelial cells: Regulators of barrier function and immune homeostasis. Nat. Rev. Immunol. 14:141-153.

Plaizier, J. C., D. O. Krause, G. N. Gozho, and B. W. McBride. 2008. Subacute ruminal acidosis in dairy cows: The physiological causes, incidence and consequences. Vet. J. 176:21-31.

Reinhardt, V., and A. Reinhardt. 1981. Natural sucking performance and age of weaning in zebu cattle. J. Agric. Sci. (Camb.) 96:309312.

Rey, M., F. Enjalbert, S. Combes, L. Cauquil, O. Bouchez, and V. Monteils. 2014. Establishment of ruminal bacterial community in dairy calves from birth to weaning is sequential. J. Appl. Microbiol. 116:245-257.

Rey, M., F. Enjalbert, and V. Monteils. 2012. Establishment of ruminal enzyme activities and fermentation capacity in dairy calves from birth through weaning. J. Dairy Sci. 95:1500-1512. 
Rieu, F., G. Fonty, and P. Gouet. 1989. Colony counts and characterization of bacteria adherent to the rumen wall and desquamated epithelial cells in conventional young lambs. Can. J. Microbiol. 35:698-705.

Roffler, B., A. Fah, S. N. Sauter, H. M. Hammon, P. Gallmann, G. Brem, and J. W. Blum. 2003. Intestinal morphology, epithelial cel proliferation, and absorptive capacity in neonatal calves fed milkborn insulin-like growth factor-1 or a colostrum extract. J. Dairy Sci. 86:1797-1806.

Sakata, T., and H. Tamate. 1978. Rumen epithelial cell proliferation accelerated by rapid increase in intraruminal butyrate. J. Dairy Sci. 61:1109-1113.

Soberon, F., E. Raffrenato, R. W. Everett, and M. E. Van Amburgh. 2012. Preweaning milk replacer intake and effects on long-term productivity of dairy calves. J. Dairy Sci. 95:783-793.

Soberon, F., and M. E. Van Amburgh. 2013. Lactation Biology Symposium: The effect of nutrient intake from milk or milk replacer of preweaned dairy calves on lactation milk yield as adults. A metaanalysis of current data. J. Anim. Sci. 91:706-712.

Steele, M. A., O. AlZahal, S. E. Greenwood, J. C. Matthews, and B W. McBride. 2013. Technical note: Use of laser capture microdissection for the localization of tissue-specific global gene expression in rumen papillae. J. Dairy Sci. 96:7748-7752.

Steele, M. A., O. AlZahal, S. E. Hook, J. C. Matthews, and B. W. McBride. 2011a. Rumen epithelial adaptation to high grain diets involves the coordinated expression of genes involved in cholesterol homeostasis. Physiol. Genomics. 43:308-316.

Steele, M. A., O. AlZhal, M. Walpole, and B. W. McBride. 2012a. Short communication: Grain-induced subacute ruminal acidosis is associated with the differential expression of IGF binding proteins in the rumen epithelium of dairy cattle in early lactation. J. Dairy Sci. 95:6072-6076.

Steele, M. A., J. Croom, M. Kahler, O. AlZahal, S. E. Hook, K. C. Plaizier, and B. W. McBride. 2011b. Bovine rumen epithelium undergoes rapid structural adaptations during grain-induced subacute ruminal acidosis. Am. J. Physiol. Regul. Integr. Comp. Physiol. 300:R1515-R1523.

Steele, M. A., L. Dionissopoulos, O. AlZahal, J. Doelman, and B. W. McBride. 2012b. Rumen epithelial adaptation to high grain diets in lactating dairy cattle involves the coordinated expression of IGF binding proteins and a cholesterolgenic enzyme. J. Dairy Sci. 95:318-327.

Steele, M. A., F. Garcia, M. Lowerison, K. Gordon, J. A. Metcalf, and M. Hurtig. 2014. Technical note: Three-dimensional imaging of rumen tissue for morphometric analysis using micro-computed tomography. J. Dairy Sci. 97:7691-7696.

Steele, M. A., C. Schiestel, O. AlZahal, L. Dionissopoulos, A. Laarman, J. C. Matthews, and B. W. McBride. 2015. The periparturient period is associated with structural and transcriptomic adaptations of rumen papillae in dairy cattle. J. Dairy Sci. 98:2583-2595.

Stone, W. C. 2004. Nutritional approaches to minimize subacute ruminal acidosis and laminitis in dairy cattle. J. Dairy Sci. 87(E. Suppl.):E13-E26.

Stout, M. J., B. Conlon, Q. Zhao, K. A. Roehl, D. M. Nelson, G. A. Macones, and I. U. Mysorekar. 2013. Identification of intracellular bacteria in the basal plate of the human placenta in term and preterm gestations. Am. J. Obstet. Gynecol. 208:226.e1-226.e7.
Tao, S., Y. Duanmu, H. Dong, J. Tian, Y. Ni, and R. Zhao. 2014a. A high-concentrate diet induced colonic epithelial barrier disruption is associated with the activating of cell apoptosis in lactating goats. BMC Vet. Res. 10:235.

Tao, S., Y. Duanmu, H. Dong, Y. Ni, J. Chen, X. Shen, and R. Zhao. 2014b. High concentrate diet induced mucosal injuries by enhancing epithelial apoptosis and inflammatory response in the hindgut of goats. PLoS ONE 9:e111596.

Taschuk, R., and P. J. Griebel. 2012. Commensal microbiome effects on mucosal immune system development in the ruminant gastrointestinal tract. Anim. Health Res. Rev. 13:129-141.

Thum, C., A. L. Cookson, D. E. Otter, W. C. McNabb, A. J. Hodgkinson, J. Dyer, and N. C. Roy. 2012. Can nutritional modulation of maternal intestinal microbiota influence the development of the infant gastrointestinal tract? J. Nutr. 142:1921-1928.

Trevisi, E., M. Amadori, F. Riva, G. Bertoni, and P. Bani. 2014 Evaluation of innate immune responses in bovine forestomachs. Res. Vet. Sci. 96:69-78.

Turnbaugh, P. J., R. E. Ley, M. A. Mahowald, E. R. Mardis, and J. I. Gordon. 2006. An obesity associated gut microbiome with increased capacity for energy harvest. Nature 444:1027-1031.

Turner, J. R. 2009. Intestinal mucosal barrier function in health and disease. Nat. Rev. Immunol. 9:799-809.

USDA. 2007. NAHMS Dairy Part 1: Reference of dairy cattle health and management practices in the United States, 2007. USDA, Washington, DC.

Ventura, B. A., M. A. G. von Keyserlingk, C. A. Schuppli, and D. M. Weary. 2013. Views on contentious practices in dairy farming: The case of early cow-calf separation. J. Dairy Sci. 96:6105-6116.

Walker, M. P., C. M. Evock-Clover, T. H. Elsasser, and E. E. Connor. 2015. Short communication: Glucagon-like peptide-2 and coccidiosis alter tight junction gene expression in the gastrointestinal tract of dairy calves. J. Dairy Sci. 98:3432-3437.

Warner, R. G., W. P. Flatt, and J. K. Loosli. 1965. Dietary factors influencing the development of the ruminant stomach. Agric. Food Chem. 4:788-792.

Wilson, D. J., T. Mutsvangwa, and G. B. Penner. 2012. Supplemental butyrate does not enhance the absorptive or barrier functions of the isolated ovine ruminal epithelia. J. Anim. Sci. 90:3153-3161.

Windeyer, M. C., K. E. Lesliea, S. M. Godden, D. C. Hodgins, K. D Lissemore, and S. J. LeBlanc. 2014. Factors associated with morbidity, mortality, and growth of dairy heifer calves up to 3 months of age. Prev. Vet. Med. 113:231-240.

Wood, K. M., S. Palmer, M. A. Steele, J. A. Metcalf, and G. B. Penner. 2015. The influence of age and weaning on permeability of the gastrointestinal tract in Holstein bull calves. J. Dairy Sci. 98:7226-7237.

Zhang, S., R. I. Albornoz, J. R. Aschenbach, D. R. Barreda, and G. B. Penner. 2013. Short-term feed restriction impairs the absorptive function of the reticulo-rumen and total tract barrier function in beef cattle. J. Anim. Sci. 91:1685-1695.

Zhou, M., Y. Chen, P. J. Griebel, and L. L. Guan. 2014. Methanogen prevalence throughout the gastrointestinal tract of pre-weaned dairy calves. Gut Microbes 5:628-638. 